\title{
Democracia y dirección científica del Estado y la sociedad
}

\section{Democracy and State and society scientific management}

\author{
René Maugé Mosquera
}

Recepción: 28 de noviembre de 2016

Aceptación: 08 de diciembre de 2016

\begin{abstract}
Resumen
El presente artículo tiene como finalidad evidenciar la necesidad de establecer la dirección del Estado y de la sociedad con nuevos paradigmas, teniendo en cuenta nuestra época, en que las naciones y las personas deben conocer y comprender las enormes mutaciones que tienen lugar en los procesos de cambio y de globalización del mundo. Uno de esos instrumentos constituye la Administración Pública teniendo como marco conceptual la teoría de los sistemas y el pensamiento complejo. El artículo expone la trama existente entre la sociedad, el Estado y los avances de la ciencia y la tecnología, teniendo como referencia la Constitución ecuatoriana del 2008.

Palabras Claves: democracia, ciencia, Estado, administración, sistemas.

\section{Abstract}

This paper aims to demonstrate the need to establish the direction of the State and society, based on new paradigms; understanding and taking into account the time in which we live in. Nations and people must be aware and understand the enormous changes that take place in the processes of globalization and change in the world. The Public Administration represents one of these instruments having as a conceptual framework the theory of systems and complex thinking. This paper exposes the existing structure between society, the State and the advances of science and technology; with reference to the Ecuadorian Constitution of 2008.
\end{abstract}

Keywords: Democracy, Science, State, Administration, Systems 


\section{Introducción}

1 encabezamiento de este artículo, responde a las necesidades $\gamma$ de nuestro tiempo, donde la conducción de nuestras sociedades y del Estado no pueden ni deben ser el fruto de la improvisación, el desconocimiento o el azar. Nuestra época se caracteriza por una transformación civilizatoria de mayor magnitud que el cambio que se operó entre los siglos XVII y XVIII, con la revolución industrial, revolución que hundió el régimen feudal y emergió el régimen capitalista. Comprender los profundos cambios económicos, tecnológicos, políticos y socio - culturales que tienen lugar en la actualidad, es indispensable para comprender nuestro tiempo, para afrontarlos y seguir el curso de nuestra época, y avizorar el futuro; superar los atrasos y problemas de nuestra sociedad, es un reto de enorme magnitud que la mayoría de ciudadanos y políticos no los perciben en todo su alcance, esto pasa en el continente y en nuestro país. Bastaría con señalar que la población del Ecuador actualmente sobrepasa los dieciséis millones de habitantes y próximamente se duplicarán; y todos ellos demandan y demandarán mejores condiciones de vida, lamentablemente esto no es parte del debate político actual en el país.

Globalización y mundialización son dos vocablos que encierran amplios conceptos para comprender los cambios y mutaciones que se dan actualmente en el mundo, en cuyo trasfondo está la revolución científicotécnica, que incide poderosamente en la vida de nuestros pueblos.

El informe elaborado el presente año por el Foro Económico Mundial, reunido en la ciudad de Davos en Suiza, afirma que la cuarta revolución industrial está en marcha, caracterizada por una sinergia y convergencia entre las diez tecnologías claves: la ingeniería de sistemas metabólicos para producir sustancias y materiales industriales, el internet de las nano cosas, nano sensores para ser insertados en seres vivos, ecosistemas de inteligencia artificial, nuevos materiales para almacenar energía, nano 
materiales bimensionales, vehículos autónomos no tripulados, optogenética, producción de órganos humanos en chips electrónicos, entre otros. Se trata de un avance tecnológico sin precedentes, pero hará que al mismo tiempo, y según el mismo informe, hasta el 2020 se perderán cinco millones de empleos, sin contar con los nuevos contingentes generacionales de personas que demandarán trabajo, a los que se sumarán los ya existentes.

Las tres revoluciones Industriales anteriores son: la primera: la revolución de la máquina a vapor; la segunda: caracterizada por la electricidad; la tercera: por la electrónica de los circuitos integrados, y la cuarta: que según Klaus Schwab, se ha iniciado y que es el producto de la convergencia de tecnologías digitales, físicas y biológicas. Esta cuarta revolución consiste en "la transición hacia nuevos sistemas que están construidos sobre la infraestructura de la revolución digital (anterior)" (Perasso, 2016). En otras palabras, la cuarta revolución, es el resultado de la concurrencia de la robótica, nanotecnología, biotecnología, tecnología de la información, inteligencia artificial y otras.

El Ecuador no está ni remotamente en el mundo científico de la cuarta revolución industrial, lo que no quiere decir que sus efectos no incidirán positiva o negativamente a su entorno social.

Cuando se dice que estamos asistiendo a un cambio de época o a un cambio civilizatorio, se refiere no sólo a los procesos de globalización de la economía, sino también a los efectos que tiene en las sociedades la revolución científico-técnica, en sus tres aspectos: revolución de la materia; revolución del conocimiento y revolución de la vida. Estos cambios y su incidencia en la sociedad ecuatoriana requieren de nuevos instrumentos para lograr los cambios necesarios ampliando y profundizando simultáneamente la democracia. 


\section{La administración pública como instrumento de ejecución de políticas democráticas}

El marco jurídico-político de la Constitución del Ecuador del 2008 ofrece un esfuerzo colectivo por encontrar nuevos paradigmas que marquen una hoja de ruta del presente y futuro para superar los problemas heredados de un pasado de dominación colonial, de una república oligárquica, de la actual imposición de formas neocoloniales que actúan básicamente, a través del poder transnacional y de patrones ideológicos que se difunden cotidianamente por medio de poderosos y sofisticados instrumentos del poder mediático, que han acentuado y reproducido en el tiempo una colonialidad del ser, del poder, del saber y de la naturaleza. ¿Qué entendemos por colonialidad del ser, colonialidad, del poder, colonialidad del saber y de la naturaleza?

- Entendemos por Colonialidad del ser la actitud y conducta que esterilizan la posibilidad de pensar con nuestra propia cabeza, pensar en el yo nacional, como nosotros, siendo presa de la dicotomía superior - inferior, que la inventaron los colonialistas para justificar la dominación y explotación de los pueblos dominados;

- Colonialidad del poder, es la supeditación del país a las políticas de subordinación, dictadas ya sea en el pasado por la Ley de Seguridad Nacional, por los lineamientos del Consenso de Washington, el Fondo Monetario y a determinados tratados internacionales que favorecen al capital transnacional;

- Colonialidad del saber, cuando aceptamos la subordinación al conocimiento del más fuerte o desarrollado como el caso del pensamiento único y del eurocentrismo;

- Colonialidad de la naturaleza, nos remite a la separación mentecuerpo-sociedad-naturaleza, postulada desde Descartes, cuando se afirmó que la ciencia moderna se estableció para el control 138 
del hombre sobre la naturaleza, el dominio absoluto sobre ella, generando los desequilibrios existentes. Superar estas formas de colonialidad es una tarea histórica del presente.

Entre los complejos problemas que tiene el Ecuador, está el resolver la responsabilidad que tienen los hombres y mujeres que conforman los gobiernos de turno, de los funcionarios o administradores públicos por el manejo eficiente de los intereses nacionales, de los de la mayoría de la población y de los recursos naturales y culturales.

No debemos olvidar que desde la década del ochenta, los gobiernos sucesivos tuvieron una política errática por no decir entreguista, en relación con los intereses nacionales y populares, como el caso de integración a la Asociación al Libre Comercio (ALCA) que dio inicio al despojo de los bienes públicos con las políticas de las privatizaciones, la compra de la deuda privada por parte del Estado que asumió la ineficiencia y el latrocinio de sectores privados llamada sucretización, la desregulación laboral, la dolarización, que llevó al país a una espantosa crisis económica, política y moral que todavía perduran sus consecuencias en el país.

Cuando nos referimos a la dirección de la sociedad y del Estado y su orientación basada en conocimientos científicos, debemos referirnos a la administración pública, teniendo en cuenta sus límites e ineficiencias, es decir, que el quehacer de la administración estatal debe responder a los propósitos y filosofía de la Constitución. No por gusto los sectores que plantean cambiar la actual Constitución son los mismos que son partidarios de las privatizaciones como la desregulación laboral, quienes aspiran a reducir a la mínima expresión las funciones sociales y democráticas del Estado.

Debemos tener en cuenta que mediante la administración pública se plasma en la práctica los objetivos y principios de la Constitución, esta debe 
ser la Constitución en acción. A través de la ciencia y la administración del Estado, se busca la consolidación de la comunidad nacional, mediante los valores democráticos y del ejercicio de un poder con responsabilidad, con el conocimiento de la realidad nacional y con una visión de futuro.

Dicho en otras palabras, como lo expresa Julio Rodríguez Arias, el primer motivo de ineficiencia se refiere a gobernantes que frecuentemente olvidan que administrar un país es aplicar la Constitución, ponerla en acción, reconocer la existencia y el valor de sus ideales, su doctrina y los supuestos básicos previamente consentidos, que es necesario realizar. La segunda causa se relaciona directamente con la calidad, el mérito profesional y la motivación de los administradores que deben cuidar de dicha preservación y manejo de los bienes públicos.

El Estado debe ser conducido democráticamente, es decir que todas las políticas deben estar orientadas al beneficio del conjunto de la población y en especial de los más necesitados, con una clara y segura precepción de los problemas a resolver, de acuerdo a la dinámica de nuestra época y del entorno internacional.

Cuando hablamos de política, o de los políticos, siempre debemos tener en cuenta que ésta es, entre otras cosas, una línea de conducta que un grupo humano, una nacionalidad, nación, gobernantes y gobernados, deben seguir para resolver problemas de organización, relaciones de cooperación y acciones político-sociales para asegurar la conservación, supervivencia, bienestar o Buen Vivir de las ciudadanas y ciudadanos.

Lo esencial en la política es la estructura del poder estatal, la participación de la ciudadanía en los asuntos del Estado para lograr una vida digna y la determinación de las formas, tareas y contenidos de la actividad del Estado, así como también la actividad y relaciones entre los diversos grupos sociales, nacionalidades, naciones y los Estados. Entre los cambios 
culturales que tienen lugar actualmente, está el de la cultura política que ha adquirido un nuevo significado en la historia del mundo; desde el punto de vista de la ciencia política es saber cuál es el contenido de esta nueva cultura mundial que deberá contar con una amplia participación de las ciudadanas y los ciudadanos en los asuntos públicos, con un elevado nivel de información y un sentido de responsabilidad cívica asociado a sistemas democráticos, en una estrecha relación entre los índices de modernización y democratización.

Una dirección científica de la sociedad necesita de una administración pública preparada y eficiente, lo que no siempre sucede por diversos factores: desconocimiento del país y de la administración pública, por funcionarios que tienen una visión estrecha del universo en que actúan y por políticos que llegan al poder y lo utilizan en beneficio propio o de grupos de interés.

\section{Nuevos enfoques y métodos}

Cabe la pregunta ¿Qué entendemos por dirección científica de la sociedad y del Estado? En primer lugar, es necesario adoptar un enfoque sistémico integral de la sociedad y sus necesidades, teniendo como instrumento metodológico la teoría de sistemas y el pensamiento complejo. En segundo lugar, se debe tener en cuenta los avances de la cibernética, que presenta un análisis de conceptos más generales de gobierno, de sistemas múltiples, aplicables como un instrumento auxiliar a la sociedad, entendida como un sistema que contiene un complejo entramado de relaciones, intereses, visiones de los seres humanos y sus instituciones. En tercer lugar, entendemos por ciencia una forma particular de conciencia social que elabora, sintetiza y sistematiza técnicamente los conocimientos sobre la realidad y el mundo circundante, descubre leyes, investiga y explica los procesos y fenómenos que son objeto de sus estudios.

La ciencia, por tanto, proporciona el conocimiento del mundo en 
sus diferentes fases y particularidades. Es importante destacar que la ciencia, como parte integrante de las fuerzas productivas a partir de la revolución científico-técnica, ocupa un lugar preponderante como fuerza dinamizadora de los procesos productivos, económicos, culturales y espirituales, pero al mismo tiempo los logros de las ciencias y las tecnologías, en manos de los grupos económicos más poderosos del planeta, son utilizados para ampliar las asimetrías sociales de riqueza y pobreza, para fines bélicos y para dominar material y espiritualmente a pueblos enteros.

\section{La democracia moderna}

La democracia moderna surgió de dos grandes procesos políticos, uno en América y otro en Europa: la independencia de las 13 colonias inglesas convertidas en los Estados Unidos de Norte América de 1776, y la Revolución francesa de 1789. En el siglo XIX se inició el proceso de independencia de América del Sur y América Central y las Antillas, dando lugar a la creación de las actuales naciones y democracias latinoamericanas. En el decurso de los dos últimos siglos, entre enormes avatares, como la descolonización de pueblos y continentes enteros y dos guerras mundiales, la democracia y sus instrumentos jurídicos y políticos han avanzado hacia una mayor participación, respeto a la voluntad de los ciudadanos y ciudadanas y reconocimiento de un conjunto de derechos humanos, a tal punto que existe una estrecha relación entre sociedad democrática, ciudadanos y derechos humanos.

En la Constitución ecuatoriana de 2008, se establece que la democracia es un elemento constitutivo del Estado, un principio fundamental de convivencia y legitimidad de las instituciones y sus representantes, así como un deber primordial del Estado para garantizar a sus habitantes el derecho a vivir en una sociedad democrática, intercultural, plurinacional y laica. Una democracia que no se apoya en la justicia, en la libertad y en la igualdad, 
es una palabra vacía, si no está unida y orientada al desarrollo económico y social para satisfacer las necesidades básicas de las personas, dado que la democracia y el desarrollo económico y social son interdependientes y se refuerzan mutuamente y, a su vez, la pobreza, el analfabetismo y los bajos niveles de producción y desarrollo humano son factores que inciden negativamente en la calidad y consolidación de la democracia. Así lo entiende la Constitución ecuatoriana del 2008, como una superación de la democracia formal a una democracia real con contenidos económicos, sociales y políticos.

La Constitución ecuatoriana establece los principios y derechos de participación en democracia de los ciudadanos y ciudadanas, así como un régimen de desarrollo que sustente y dinamice la capacidad productiva para lograr mejores condiciones de vida para los ecuatorianos. El régimen de desarrollo es definido como el conjunto organizado, sostenible y dinámico de los sistemas económicos, políticos, socioculturales y ambientales, que garantizan la realización del buen vivir; el Sumak Kawsay.

La democracia moderna es una síntesis de las ideas de libertad e igualdad, no sólo para unos pocos, como las personas libres en la democracia de los antiguos, cuyas sociedades eran esclavistas, como es el caso de la primera democracia instaurada en Atenas en 508 A.C., y posteriormente en Roma. La democracia moderna, desde el punto de vista político, es una forma de Estado y de gobierno cuya característica esencial y distintiva, en todas sus diversas acepciones, es la distribución del poder político entre el mayor número de sus destinatarios. Sus fundamentos están en el cumplimiento de los derechos humanos.

La democracia en América Latina es el resultado del movimiento independentista con la creación de los nuevos Estados bajo la forma republicana de gobierno que en sus orígenes, desde el punto de vista social y político, mantuvieron arcaicas formas heredadas del colonialismo, eran democracias embrionarias, inorgánicas y no institucionalizadas como lo 
entendemos ahora.

En nuestro país, aunque sea un contrasentido, a inicios de la época republicana, la democracia era excluyente de las mayorías, por razones económicas, sociales, de género y de pertenencia étnica. Desde 1830, año de creación del Estado ecuatoriano, después de su separación de Colombia, la lucha por la democracia contra autoritarismos y dictaduras ha-sido una constante como también para superar la democracia formal excluyente de las mayorías, la democracia real es el anhelo y la esperanza del pueblo ecuatoriano.

La Constitución de 2008, fruto de una secular y larga lucha popular contra las discriminaciones, exclusiones y políticas contrarias a las mayorías y, en las últimas décadas una resistencia a las expoliadoras políticas neoliberales, establece la democracia participativa, recogiendo el concepto lanzado en la década del 60 del siglo XX. Esta Constitución establece que:

"las ciudadanas y ciudadanos, en forma individual y colectiva, participarán de manera protagónica en la toma de decisiones, planificación y gestión de los asuntos públicos, y en el control popular de las instituciones del Estado y la sociedad, y de sus representantes, en un proceso permanente de construcción del poder ciudadano. La participación se orientará por los principios de igualdad, autonomía, deliberación pública, respeto a la diferencia, control popular, solidaridad e interculturalidad. La participación de la ciudadanía en todos los asuntos de interés público es un derecho, que se ejercerá a través de los mecanismos de la democracia representativa, directa y comunitaria”. (Art. 95 de la Constitución de la República del Ecuador). 
La Democracia Participativa que consta en la Constitución, consiste en tomar parte en persona, es un compromiso y un esfuerzo activo. Un punto de partida de la empresa de la democracia participativa, es la opinión pública, es elevar la opinión pública con base a un conocimiento bien informado, es transformar la información en competencia, en dominio cognitivo, es, como hemos dicho, unir la ciencia y la cultura popular. La información es patrimonio del pueblo y los funcionarios públicos son administradores de esa información, no los dueños, como todavía falsamente se cree.

El sistema democrático ecuatoriano formulado en la Constitución del 2008 constituye un nuevo marco estructural o democracia orgánica, esto es, funcionando ésta como un todo, como un sistema de partes articuladas e interrelacionadas entre sí, y como un método de adecuación mutua o dialéctica entre medios y fines; entre funciones y resultados cuantitativos y cualitativos. La concepción sistémica de la democracia se inscribe como un sistema de vida o, como se expresa en el preámbulo de la Constitución, cuando dice que el pueblo soberano del Ecuador:

"ha decidido construir una nueva forma de convivencia ciudadana, en diversidad y armonía con la naturaleza, para alcanzar el buen vivir, el sumak kawsay; una sociedad que respeta, en todas sus dimensiones, la dignidad de las personas y las colectividades; Un país democrático, comprometido con la integración latinoamericana - sueño de Bolívar y Alfaro-, la paz y la solidaridad con todos los pueblos de la tierra”.

El sistema democrático establecido en la Constitución se fundamenta en la participación y el diálogo permanente, por eso, se consigna en dicho texto, los siguientes derechos de participación: 
1. Elegir y ser elegido

2. Participar en los asuntos de interés público

3. Presentar proyectos de iniciativa popular normativa

4. Ser consultados

5. Fiscalizar los actos del poder público

6. Revocar el mandato que hayan conferido a las autoridades de elección popular

7. Desempeñar empleos y funciones públicas con base en méritos y capacidades, y en un sistema de selección y designación transparente, incluyente, equitativo, pluralista y democrático, que garantice su participación, con criterios de equidad y paridad de género, igualdad de oportunidades para las personas con discapacidad y participación inter-generacional.

8. Conformar partidos y movimientos políticos, afiliarse o desafiliarse libremente de ellos y participar en todas las decisiones que éstos adopten.

Las personas extranjeras gozarán de estos derechos en lo que les sea aplicable". (Art. $61 \mathrm{CRE})$

Gozar de estos derechos no sólo se requiere enunciarlos, sino llevarlos a la práctica, para lo cual es indispensable fortalecer la educación científica y cívica de toda la población, incluidos los funcionarios públicos mediante el establecimiento de nuevos parámetros para afirmar y conseguir que la nacionalidad y el intelecto ocupen un papel central en los asuntos de los ciudadanos y ciudadanas. Estos derechos son complementados por los 
principios de participación: igualdad, autonomía, deliberación pública respecto a la diferencia, control popular, solidaridad e interculturalidad. Estos derechos y principios tienen un objetivo central: la construcción de un poder ciudadano que desmonte y enfrente a los poderes oligárquicos y transnacionales.

En esta línea de acción, es un deber del Estado "promover e impulsar la ciencia y la tecnología, las artes, los saberes ancestrales y, en general, actividades de la iniciativa creativa comunitaria, asociativa, cooperativa y privada" (Art. 277 de la CRE); por esta razón, para la consecución del buen vivir, a las personas y a las colectividades, y sus diversas formas organizativas, les corresponde: "1. Participar en todas las fases y espacios de gestión pública y de planificación del desarrollo nacional y local, y en la ejecución y control del cumplimiento de los planes de desarrollo en todos sus niveles; 2. Producir, intercambiar y consumir bienes y servicios con responsabilidad social y ambiental" (Art. 278 de la CRE). En otras palabras el sistema nacional que lo defino en términos concretos como nacional, democrático, laico y científico es el instrumento clave para fortalecer las instituciones democráticas, promover el potencial humano, mitigar la pobreza y fomentar una mejor convivencia entre las personas, pueblos y nacionalidades.

La Democracia y la Dirección Científica del Estado y la Sociedad, requiere de una población culta e ilustrada; por ello el sistema de educación superior apunta a tener ciudadanos y ciudadanas con capacidad para dirigir y resolver los problemas que se presentan en el decurso de la vida, por eso junto a un desarrollo económico sostenible, la Constitución, en su artículo 350, dispone que:

"El sistema de educación superior tiene como finalidad la formación académica y profesional con visión científica y humanista; la 
investigación científica y tecnológica; la innovación, promoción, desarrollo y difusión de los saberes y las culturas; la construcción de soluciones para los problemas del país, en relación con los objetivos del régimen de desarrollo."

Como vemos, la Asamblea Constituyente, que formuló la Constitución del 2008, proyectó una visión de un Estado realmente democrático en su forma y contenido, un Estado que sea el representante de los derechos y anhelos del pueblo, en el que se respeten los derechos contenidos en ella y en los instrumentos internacionales, a los que deben tener acceso todas las personas que habitan en el territorio nacional.

El Ecuador tiene un marco constitucional y legal, que le franquea la posibilidad, de ser aplicado con conciencia, avanzar en la dirección científica del Estado y la sociedad, añadiendo que es necesario, paralelamente, para unir la ciencia con la cultura popular y el desarrollo económico. Pero además, se requiere de una sólida voluntad política de los gobiernos para llevar a cabo en el tiempo una política de Estado que haga cumplir las formulaciones constitucionales, porque de lo contrario, estaríamos en presencia de una Constitución de papel que nadie la cumple. Al respecto, el rol del Estado como eje principal del sistema político de la sociedad es fundamental y no secundario en la elaboración de políticas públicas, aplicando principios como el de la racionalidad, descentralización, interés público, participación social y planificación. A pesar de las consecuencias desastrosas, como resultado de las políticas neoliberales para la vida de millones de seres humanos, sigue en vigencia el debate sobre el rol del Estado y su accionar en la economía. El dilema es, si el Estado está al servicio de unas élites o al servicio de la mayoría del pueblo. 


\section{Derecho Administrativo Público y Gestión Científica del Estado y la Sociedad}

En el primer cuarto del siglo XX, se producen grandes cambios sociopolíticos: la Revolución de octubre de 1917 en Rusia, no sólo sacudió los cimientos del imperio zarista y proyectó la conclusión de la Primera Guerra Mundial, sino que determinó el cambio de algunos paradigmas en el mundo laboral y en las ciencias económicas y administrativas, y significó un nuevo momento en la geopolítica mundial con el tratado de Versalles de 1919, que estableció las condiciones de paz después de la $1^{\text {a }}$ Guerra Mundial.

En los inicios del nacimiento de la primera experiencia socialista, al formarse la Unión Soviética en los años veinte del siglo pasado se inauguraron los planes quinquenales y la planificación de la economía con una visión estratégica de mediano y largo plazo. Después de la Segunda Guerra Mundial, adoptaron la planificación estratégica y planes de mediano y largo plazo aquellos países que debían reparar los estragos causados por la guerra y quienes optaron por la vía del desarrollo socialista como China y los países de Europa del Este.

En este período de entreguerras y con la creación de la Organización de las Naciones Unidas (ONU), las ciencias de las políticas públicas tomaron un nuevo impulso, en 1951 a partir de la propuesta seminal de Harold Lasswell quién en su obra "El futuro de la ciencia política" (1971), desde una perspectiva multidisciplinaria y pragmática, planteó imprimir racionalidad en la política y en el trabajo gubernamental, para enfrentar los grandes problemas sociales, económicos y políticos, conjuntando los esfuerzos públicos y privados, partiendo del criterio que, tratándose de problemas de poder entre actores e instituciones, se debe aunar esfuerzos en la formación de las decisiones públicas para lograr alternativas de cambio social compatibles con la democracia. Lasswell fue el autor de la fórmula: "Quién dice que, a quién, por qué canal y con qué efecto" convertido en esquema de la sociología de 
la comunicación".

En este período, a más de los planes y programas de desarrollo impulsados por la ONU y sus organismos especializados, aparecieron nuevos fundamentos de las ciencias administrativas y de las políticas públicas. El concepto de ciencias políticas públicas y planificación está orientado a superar la intervención del azar, el desconocimiento y la improvisación y establecer la política como actividad previsible y planificable, considerando el entorno nacional e internacional de manera real y objetiva, alejado de prejuicios y subjetivismos; aumentar la racionalidad en las decisiones públicas, adoptar esquemas de investigación empírica, la formulación de hipótesis, elevar los conocimientos de toda la población teniendo como meta la escolaridad media de diez a doce años para todos los habitantes, en definitiva, planificar las políticas públicas mediante la formulación de una agenda pública.

El nuevo constitucionalismo ecuatoriano define a la administración pública como un servicio a la colectividad que se conduce por los principios de eficacia, calidad, jerarquía, desconcentración, descentralización, coordinación, participación, planificación, transparencia y evaluación (Art. 227 - CRE) y añade que "El Estado garantiza la formación y capacitación continua de servicios, servidoras y servidores públicos, a través de las escuelas, institutos, academias y programas de formación o capacitación del sector público; la coordinación con instituciones nacionales e internacionales que operen bajo acuerdos con el Estado (Art. 234 - CRE).

A más de la noción de Administración Pública, es necesario identificar aquellos elementos que perfilan a la Administración Pública como un sistema diferenciado de otras instituciones, porque en los Estados modernos existen múltiples instancias de poder subordinadas unas a otras, una clara diferenciación con respecto a las organizaciones privadas, cooperativas o comunitarias. 
La Administración Pública debe apuntar a objetivos estratégicos claros, objetivos que en décadas pasadas se denominaban en la legislación ecuatoriana, "Objetivos Nacionales Permanentes", en este sentido, tiene un carácter de ciencia, llamada también Ciencia de la Administración con sus características reales en su relación con el poder y la sociedad; por ejemplo, son objetivos estratégicos: el buen vivir, la educación en todos sus niveles, la seguridad alimentaria, la defensa, soberanía e independencia nacionales, la paz, entre otros. La Ciencia de la Administración juega un rol importante en la formulación de políticas públicas y, en consecuencia, es parte de los procesos políticos y del enfrentamiento de visiones sobre el desarrollo y la redistribución de la renta nacional.

En el ámbito de las políticas públicas, la Ciencia de la Administración está unida a la noción del Estado y su rol en la sociedad, siendo -según Carles Ramió Matas- sus funciones fundamentales son:

a) Reglamentar las relaciones entre la sociedad y el entorno externo

b) Reglamentar las demandas y los reclamos entre los miembros del sistema en el orden interno

c) Asegurar la capacidad de acción del sistema político-administrativo, con recursos fiscales y humanos

d) Prestación de abastecimiento y servicios

e) Conducción del desarrollo social hacia determinados objetivos (crecimiento económico, atención y mejoramiento de la salud, ampliación y elevación del nivel educativo). (Ramió Matas, 2001)

Existe una relación directa entre poder, política, desarrollo, democracia y Ciencia de la Administración. Los fundamentos de la ciencia y administración 
moderna están orientados a que los gobiernos puedan ejercer una influencia notable en el crecimiento económico y humano, salvo que se trate de gobiernos corruptos, oligárquicos o neoliberales que administran el patrimonio público en función de sus intereses particulares, de grupos o subordinados a los poderes transnacionales. Si los gobiernos hacen lo que deben hacer, el crecimiento se acelera. Por el contrario, si hacen muy poco o lo hacen mal, el desarrollo se retarda (Lewis, 1976: 446). La administración pública no es neutra ni comporta solamente un conjunto de preceptos y disposiciones legales, sino que su actuación está determinado por la voluntad política de los gobiernos que los impulsa.

Partiendo de los drásticos procesos que tienen lugar en el mundo como consecuencia de la revolución científico-técnica, han surgido desde la década de los sesenta, nuevas escuelas y teorías para estructurar un nuevo Estado desde las más amplias perspectivas, teniendo en cuenta su situación real y sus relaciones con el poder y la sociedad.

Desde el pensamiento neoliberal, se planteó una nueva teoría económica de la política partiendo de la reducción del Estado a su mínima expresión y la transferencia de lo público a lo privado, más conocido como política de las privatizaciones y como expresa Marcelo Reinoso Navarro:

"Los resultados en el Ecuador ya los conocemos: el desmantelamiento del aparato Estatal, la desinversión en actividades productivas a cargo del sector público para hacerlas improductivas y la concesión o venta de dichas actividades a costos de liquidación para inversionistas privados, medidas de ajuste estructural para "compensar" a los ciudadanos empobrecidos por los procesos de reformas fracasadas que originaron desequilibrios en la distribución de los recursos y concentración de capital en pocas manos; migración a los centros 
urbanos y crecimiento sin ordenamiento territorial, entre otras, son las funestas consecuencias" (Reinoso Navarro, 2011: 14)

Frente al caos y drama creado por la aplicación de estas políticas neoliberales ${ }^{1}$, el país reaccionó y a partir del 2007, se inicia un nuevo momento político bajo los lineamientos de la denominada Revolución Ciudadana. La administración pública del país se orienta a materializar la construcción del Estado Plurinacional e Intercultural y alcanzar el objetivo estratégico del buen vivir. Para ello, se establece una planificación estratégica encaminada a mejorar la administración pública. El Presidente de la República Rafael Correa, mediante decreto No. 555 dispuso la implementación del proyecto de "Gestión Pública Institucional y Gobiernos por Resultados- GPR", en todas las instituciones de la Administración Pública Central e institucional a cargo de la Secretaría Nacional de la Administración Pública.

Dicho decreto establece, en el artículo primero: "se dispone la implementación del Proyecto Gobierno por Resultados - GPR en todas las instituciones de la Administración Pública Central, institucional y dependiente de la Función Ejecutiva, a cargo de la Secretaria Nacional de la Administración Pública", cuyo objetivo es implementar una metodología de planificación y gestión de mapas estratégicos, objetos, indicadores, proyectos, planes y procesos mediante la aplicación de mejores prácticas y uso de tecnologías de información que los hagan posibles. Los beneficios que se esperan obtener de la Administración Pública por procesos y proyectos son: Gestión integral y sistémica, direccionamiento de objetivos, uso de herramientas tecnológicas, selección de personal por meritocracia, gestión de la cultura e innovación, gestión de cambio radical, certificación de la calidad. Complementan al Gobierno por Resultados los decretos presidenciales, 726, 729,737 y otras disposiciones contenidas en leyes y reglamentos.

1 Además de las consecuencias citadas por Reinoso Navarro, se produjo el desarraigo del $12 \%$ de la población que se vio obligada a emigrar a otros países. 
A título de ejemplo, el Consejo Nacional Electoral que, de acuerdo a la Constitución del 2008, es una de las cinco funciones del poder del Estado, superando la teoría de la tripartición de poderes, elaboró su Plan Estratégico Institucional 2014 - 2017, mediante resolución N. PLE - CNE 2-2-9-2014, teniendo en cuenta la Constitución de la República, los objetivos nacionales, establecidos en el Plan Nacional del Buen Vivir 2009 - 2013. Además, el Consejo Nacional Electoral se ha comprometido a dirigir sus esfuerzos hacia la implementación de un sistema de Gestión de Calidad que garantice procesos eleccionarios participativos, equitativos, igualitarios, interculturales, libres y democráticos. Con la finalidad de materializar la visión y misión institucional, el Consejo Nacional Electoral -cimentado en criterios de calidad y eficienciaha establecido seis ejes estratégicos que son: 1. Procesos democráticos transparentes; 2. Soberanía Electoral; 3. Fortalecimiento institucional; 4. Fortalecimiento de organizaciones políticas; 5. Capacitación democrática; y, 6. El CNE en el contexto internacional.

Para plasmar estos ejes estratégicos el CNE y la OEA suscribieron un acuerdo de cooperación para establecer normas de gestión de calidad ISO/TS 17582:2014. El CNE empeñó su palabra y obtuvo, con el apoyo del Departamento para la Cooperación de Gestión de calidad en Autoridades Electorales de América Latina, la capacitación de funcionarios de la institución. Luego de cumplir con varias etapas, la auditoria interna y preauditoría con asesoría técnica de los de los consultores externos recomendaron la certificación, el CNE obtuvo la certificación ISO 150/TS17582: 14 - ISO 9001:2008, el 13 de mayo del 2016.

La diferencia entre los países industrializados y los de menor desarrollo o en vías de desarrollo, a los que nos motejan de tercermundistas, consiste en que los países industrialmente desarrollados diseñan, crean, producen y exportan ciencia transferida en procesos sistemáticos de alta tecnología. Mientras que los países de menor desarrollo se constituyen en 
importadores de conocimientos para orientar su crecimiento económico. Por eso, la Constitución de la República, los elementos constitutivos del Estado, la participación y organización del poder, la organización territorial del Estado, el Régimen de Desarrollo, los Derechos y Regímenes del Buen Vivir, los Planes Nacionales para el Buen Vivir y la construcción de un Estado Plurinacional e Intercultural contienen una ruptura conceptual que implica actuar bajo tres condiciones: sostenibilidad económica, desarrollo de capacidades humanas y oportunidades sociales, y acumulación de capital productivo necesario para cambiar el patrón de especialización y el modo de acumulación de la economía, mediante el cambio de la matriz productiva.

Si bien es cierto que en una sociedad como la ecuatoriana existen y se dan hechos espontáneos, no programados, el marco constitucional determina y permite establecer líneas de conductas de parte de los gobiernos, orientadas hacia fines concretos, que consten en los programas del gobierno central y de los gobiernos provinciales, así como en los diferentes sistemas y subsistemas de los organismos y organizaciones que actúan constantemente sobre el complejo sistema social a fin de lograr determinados resultados y, de esta manera, evitar subjetivismos personales, oponerse a conductas espontáneas, respuestas automáticas sin mayor reflexión ante los problemas y necesidades que cotidianamente se presentan en la sociedad, en el diario convivir.

El XIII Congreso Internacional de Administración que se celebró en 1964 en Nueva York, con la presencia de dos mil delegados de cien países, que representaron a poderosas empresas, lo hicieron bajo el lema: "El progreso de la humanidad a través del perfeccionamiento de la administración”, así como otros congresos, determinaron pautas en el orden de diseñar administraciones públicas eficientes y científicas.

Si el perfeccionamiento científico de la Administración Pública ya era una necesidad en la década de los años sesenta, como consecuencia de las exigencias del desarrollo de la producción moderna y del crecimiento 
del desarrollo social, mucho más en esta época de la revolución científicotécnica, del aumento exponencial de la población y de nuevos factores negativos como el cambio climático, catástrofes naturales, deterioro de la naturaleza, contaminación ambiental, narcotráfico, crimen internacional organizado, entre otros problemas globales que afectan a las naciones.

Los métodos actuales de programación expuestos por diferentes escuelas de Administración Pública, de la gestión de los sistemas gubernamentales, económicos y sociales, son conscientes de la necesidad de la planificación orientadas al servicio de las mayorías, salvo el neoliberalismo o neo-conservadurismo y de autores como Ludwig von Mises, defensor de la idea de que las fuerzas del mercado son el único regulador de la economía. Mises afirma: "No existe otra planificación en aras de la libertad y del bienestar general que no sea el dejar campo de acción libre al sistema de mercado" (1952: 17). Sin embargo, ni antes, ni en el contexto actual, las fuerzas ciegas del mercado no están en condiciones de asegurar el progreso social de siete mil millones de personas en el planeta, ni de sociedades de menor desarrollo como la nuestra, si no es a través del manejo eficiente de la producción económica, del cambio de mentalidad y del diseño de nuevos paradigmas, ya que la vida y la sobrevivencia con dignidad de los pueblos exige la planificación consciente de la economía industrial y agrícola y de toda la vida social. Las bases constitucionales jurídicas y metodológicas de la administración pública no son suficientes si no están acompañadas de la solución de los acuciantes problemas económicos con la ayuda de medidas sociopolíticas y teniendo en cuenta los factores socio-psicológicos de las poblaciones y la utilización de las modernas tecnologías de la información. 


\section{Del gobierno espontáneo al gobierno científico de la sociedad}

Para una mejor comprensión del planteamiento sobre la necesidad de una dirección científica de la sociedad y del Estado, que está llamado a dirigirla a través de políticas destinadas a la totalidad o mayoría de la población y no en función de unos pocos, es imprescindible comprender y reflexionar, que no es lo mismo dirigir por parte de un gobierno al Estado en función de los intereses ya sea del cincuenta, veinte, cinco o uno por ciento de la población, como se da en muchos Estados altamente industrializados, donde el uno por ciento de la población tiene tantos recursos como el noventa y nueve por ciento restante.

La nueva organización territorial del Estado, establecida en la Constitución del 2008, nos sitúa en un contexto espacio-temporal deslocalizado, al definir que: "Los gobiernos autónomos descentralizados gozarán de autonomía política y financiera, y se regirán por los principios de solidaridad, subsidiariedad, equidad territorial, integración y participación ciudadana. En ningún caso el ejercicio de la autonomía permitirá la secesión del territorio nacional". (Art. $238 \mathrm{CRE}$ )

Aquí hay que tener en cuenta lo que plantea el principal principio de organización social: la democracia participativa, siendo que la novedad en las sociedades modernas radica en que obtiene su unidad e integración por diferenciación funcional, a diferencia de las sociedades tradicionales que lo hacían por procesos de homogenización territorial y en algunos casos étnicos y culturales. Si bien el vocablo globalización está en el pensamiento de los hombres y mujeres del mundo, pero con diversas comprensiones y, como bien expresa Augusto de Venanzi: "hay que pensar en global, con comer, amar y creer en local"; dicho en otras palabras, hay que reconstruir cotidianamente a la nación ecuatoriana, amarla y creer en ella, nación a la que también denominamos con el vocablo Patria que etimológicamente significa la tierra de nuestros padres y de nuestros antepasados. Pero además, las sociedades 
crean, recrean y participan en distintos ámbitos, como la economía, la política, la ciencia, el derecho y la religión, que se expresan además como formas de consciencia social y actividades como el deporte. Esto es lo que representa el llamado politeísmo funcional.

Cuando pensamos en una nueva administración pública, desde el punto de vista científico, debemos pensar y actuar a partir de la teoría de sistemas y del pensamiento complejo, entendiendo de partida, que con estos instrumentos metodológicos, tenemos una capacidad de procesar mayor información, porque si aspiramos a lograr la comprensión de un hecho particular, como los que se dan en la administración pública, se lo debe ver en el marco de la totalidad de los circuitos completos que sean relevantes para ese hecho y, como lo expresa Castells (2000: 29): “Todas las tendencias de cambio que constituyen nuestro nuevo y confuso mundo están emparentadas y podemos sacar sentido a su interacción”, porque ciertamente nos hallamos en una era de cambios rápidos, en realidad a la entrada de una nueva y desconcertante civilización; pero es nuestro deber, como seres inteligentes, identificar y ordenar las fuerzas en juego, porque lo que parece caos y ruptura, podría representar, en gran medida, rasgos de un nuevo orden que no terminamos de aprender o entender.

La teoría de los sistemas nos permite comprender tanto las crisis del capitalismo como del socialismo, ocurridas en los países de mayor desarrollo, en los emergentes y en los de menor desarrollo, teniendo en cuenta la existencia de tres sistemas fundamentales: a) Sistema económico; b) Sistema político; y, c) Sistema socio-cultural.

Estos sistemas están compuestos por otros subsistemas y, todos en conjunto, conforman un sistema integral nacional, que posee una organización interna a la que una administración público-científica puede y debe darle un modo específico de interacción e interconexión entre los competentes que la conforman, ya que el sistema integral no es armonioso ni lineal, sino 
contradictorio por naturaleza. Hay que tener en cuenta que un sistema es un proceso, razón por la cual, la estructura no es sólo espacial, sino también de tiempo, elemento que tiene mucha importancia en el sistema integral.

El concepto más general de dirección lo ha formulado la cibernética, que es la ciencia que estudia comparativamente los sistemas de comunicación y regulación automática de los seres vivos, a través de sistemas electrónicos y mecánicos. La cibernética es la ciencia que sintetiza las leyes que rigen la dirección en la naturaleza viva, en la sociedad humana y en la industria. Consecuentemente, el proceso de dirección científica de la Administración Pública no es otra cosa que el ordenamiento del sistema socio-económico y político de la sociedad.

Desde el punto de vista de la información, la cibernética es la ciencia relacionada con las formas de captar, conservar, transformar y utilizar la información; las relaciones de gobierno como poder, son parte de las relaciones sociales, de las relaciones de los ciudadanos con el gobierno, y viceversa. Son relaciones entre colectividades humanas; son las relaciones internas de las colectividades existentes, iguales pero diferentes, que requieren o establecen coordinación en las actividades concretas por su supervivencia y desarrollo.

Los principios teóricos de la cibernética que resumen el comportamiento de los seres vivos son:

1. Principio de simplicidad

2. Principio de reactividad

3. Principio de regulación

4. Principio de autonomía

5. Principio de curiosidad 


\section{Principio de coherencia \\ 7. Principio de sociedad \\ 8. Principio de la individualidad}

Por los límites y el propósito de este artículo, no detallo cada uno de estos principios, pero debo destacar el pensamiento del economista ecuatoriano Antonio Morales Rivas, en su ensayo titulado "La muerte en los números y el poder de la ignorancia" (Morales, 2016), quién sostiene que existe una paradoja en la sociedad del conocimiento, que consiste en que también se genera una crisis de civilización tanto en el capitalismo como en las economías centralizadas a través de políticas públicas fallidas y catastróficas en el sistema social, por una suerte de crisis de mentalidades, causada por la ignorancia, la falta de conciencia y visión de largo alcance, sin consistencia con el mundo real, es una crisis de conocimiento, en que impera una inteligencia ciega que destruye los conjuntos de sistemas y subsistemas y las totalidades, rompiendo los patrones de organización del sistema sin observar las partes de un contexto mayor.

La ignorancia actúa como un contrapoder negativo frente al conocimiento que es el que crea conciencia, vocablo compuesto que significa "con-conocimiento". La ignorancia de las elites y de los pueblos es generada y alimentada por el "management" bien "marqueteado" como generador de info-polución, que significa polución de la información y que consiste en trasmitir una enorme cantidad inconexa de noticias, ocultando las verdaderas y las que deberían interesar a la mayoría de las personas. Como bien destaca Edgar Morin (2013) al afirmar que: "El hombre ignora su ignorancia".

El advenimiento de esta "nueva civilización es denominada sociotrónica - fotontrónica, que enseña a pensar el mundo como un sistema 
total de interdependencias económico-sociales en los campos de acción basados en conceptos sistémicos" (Morales Rivas: 2016) que, a su vez, fundamenta los principios integradores de las ciencias cognitivas (cognitive sciences), dando soporte a los contenidos del pensamiento complejo.

Este poder de la ignorancia es el que impide, a millones de personas, ver la esencia de la democracia verdadera, en sus contenidos económicos, sociales y políticos, y no sólo instrumental, reducida a procesos electorales cada cierto tiempo. Ver y comprender que los humanos tenemos un solo planeta limitado, que se necesita más que ofertas de campañas de dudosa factura, un programa integral de cambio en la base socio económica y política, de actitudes en relación con el ejercicio del poder y en relación con el medio ambiente, un cambio que debe comenzar con la educación desde los niveles de enseñanza primaria, como parte de una nueva cultura cívico-nacional, democrática y científica, masiva para todo el pueblo. Todo esto subyace en la formación de una nueva Administración Pública que entiende que la política y la administración del Estado son para servir a la sociedad y no para servirse del Estado en detrimento de la sociedad.

\section{Conclusiones}

Para dirigir científicamente a la sociedad, es necesario concebirla en su conjunto y como un sistema integral, autogobernado, elaborar mecanismos de dirección que se expresan en la administración pública. Se debe contar con estrategias claras, instituciones sólidas, dirigentes preparados, eficaces y honestos y un pueblo culto e informado.

El primer paso de una política pública nacional de carácter científico, es hacer un inventario de los recursos disponibles, porque eso evita desperdicios, por más buena intención que se tenga, limitaría la selección de objetivos posibles, el modo de utilizar los recursos, limitaría también las 
políticas a seguir y medir la incidencia de los recursos obtenidos o existentes sobre la sociedad, y, finalmente, hacer un balance de las políticas en el manejo de esos recursos en el tiempo. La capacidad de desarrollo de un país, de una comunidad está dada por los recursos disponibles actuales y potenciales, los factores materiales y espirituales y la habilidad para su manejo, valorización y utilización prudente y oportuna.

La dirección científica y consciente de la sociedad requiere el conocimiento del mapa geopolítico y geoeconómico del mundo, comprender la era de la globalización y avanzar en el conocimiento de los cambios tecnológicos.

Es difícil conseguir la construcción de una sociedad democrática, solidaria, participativa, multicultural e intercultural, renunciando al rol del Estado como lo pretenden las actuales tendencias neoliberales. Renunciar al rol del Estado, en los actuales momentos, es incrementar la pobreza y aumentar la concentración de la riqueza. La incapacidad de gobernar tiene un eslabón crítico: la falta de voluntad política de quienes, circunstancialmente gobiernan, se someten a los dictados de la empresas transnacionales, como ceden a la presión de los grupos económicos de poder y actúan coludidos a los dictados del capital financiero nacional e internacional. 


\section{Bibliografía}

Asamblea Nacional del Ecuador. (2008). Constitución de la República del Ecuador. Quito, Ecuador.

Bovero, M. y V. Paze. (2014). La democracia en nueve lecciones. Madrid: Trotta.

Castells, M. (2000). Era de la Información. Volumen I. Economía, Sociedad y Cultura. Madrid: Alianza Editorial

Consejo Nacional Electoral. (2012). Ley Orgánica Electoral y de Organizaciones Políticas de la República del Ecuador. Código de la Democracia. Quito: El Telégrafo.

De Venanzi, A. (2002). Globalización y Corporación: El Orden Social en el Siglo XXI. Barcelona: Anthropos Editorial

Enmerich, G. y V. Alarcón. (2007). Tratado de Ciencia Política. México: Antrophos.

Estatuto del Régimen Jurídico Administrativo de la Función Ejecutiva.- R.O No. 536 del 18-03-2002 y Reformas

Fritjof, C. (2013). La Trama de la Vida - Una nueva perspectiva de los sistemas vivos. Barcelona: Anagrama.

La Enciclopedia - 2004 - Madrid - Editorial Salvat.

Lasswell, H. (1971). El futuro de la ciencia política. Madrid: Tecnos.

Lewis, W. A. (1976). Teoría del Desarrollo Económico. Bogotá: Fondo de Cultura Económica.

Ley de Modernización - Corporación de Estudios y Publicaciones - 2013 R.O. No. 349 del 31-12-1993 
Morales Rivas, A. (2016). La muerte en los Números y el Poder de la Ignorancia. 2016. En prensa.

Morin, E. (2001). El método I. La naturaleza de la naturaleza. Madrid: Cátedra.

Perasso, V. (2016). Qué es la cuarta revolución industrial (y por qué debería preocuparnos). BBC Mundo. Recuperado de https://goo.gl/6b11OK

Pérez Camacho, E. (2006). Derecho Administrativo. Ecuador: Corporación de Estudio y Publicaciones

Presidencia de la República del Ecuador. (2010). Decreto presidencial - 555.

Presidencia de la República del Ecuador. (2011). Decreto presidencial - 726.

Presidencia de la República del Ecuador. (2011). Decreto presidencial - 729.

Presidencia de la República del Ecuador. (2015). Decreto presidencial - 737.

Ramió Matas, C. 2001. Las Administraciones Públicas, en Política y gobierno en España. Valencia: Tirant lo Blanch. 531-560

Reinoso Navarro, M. (2011). Gestión Pública Institucional y Gobierno por Resultados. Quito: IAEN.

Senplades. (2009). Plan Nacional de Desarrollo para el Buen Vivir 2009 2013. Quito.

Senplades. (2010). Los Nuevos Retos de América Latina Socialismo y Sumak Kawsay. Quito.

Supiot, A. (2013). “Grandeza y Miseria del Estado Social”. En New Left Review. Ecuador: IAEN-Universidad de Postgrado del Estado. 
Tenzer, N. (1991). La sociedad despolitizada. Ensayo sobre los fundamentos de la Política. Buenos Aires: Paidós.

Von Mises, L. (1952). Planning for Freedom and other Essays and Adresses Indianapolis: Liberty Fund 